\title{
Severe Cutaneous Adverse Reactions to Drugs in Latin America: The RACGRAD Study
}

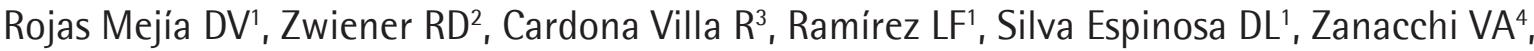 \\ Piraino Sosa $\mathrm{P}^{5}$, Ensina LF ${ }^{6}$, Giavina Bianchi $\mathrm{P}^{7}$, Coelho Portilho $\mathrm{N}^{7}$, Vivolo Aún $\mathrm{M}^{7}$, Matos Benavides $\mathrm{E}^{8}$, \\ Martínez Ruíz DM ${ }^{1}$, Jares $\mathrm{E}^{9}$, Serrano Reyes $\mathrm{CD}^{1}$
}

\author{
'Fundación Valle del Lili, Universidad Icesi, Cali, Colombia \\ ${ }^{2}$ Hospital Universitario Austral, Buenos Aires, Argentina \\ ${ }^{3}$ Universidad de Antioquia, Medellin, Colombia \\ ${ }^{4}$ Hospital San Roque de Córdoba, Cordoba, Argentina \\ ${ }^{5}$ Hospital Central, Asunción, Paraguay \\ ${ }^{6}$ Universidad Federal de São Paulo (UNIFESP), Sao Pablo, Brasil. \\ ${ }^{7}$ Universidad de São Paulo (USP), Sao Pablo, Brasil \\ ${ }^{8}$ Instituto Nacional de Salud del Niño, Lima, Perú \\ ${ }^{9}$ Fundación LIBRA, Buenos Aires, Argentina
}

J Investig Allergol Clin Immunol 2021; Vol. 31(4): 322-331

doi: 10.18176/jiaci.0497

\begin{abstract}
Background: Severe cutaneous adverse reactions to drugs (SCARs) are associated with high morbidity and mortality and with sequelae. Objective: To characterize patients with SCARs in 8 health care institutions in Latin America.

Methods: We performed a cross-sectional, descriptive, multicenter study of patients diagnosed with SCARs in Latin America between January 2009 and December 2018. The analysis was carried out using a database in BD Clinic.

Results: We collected 70 patients, of whom $42(60 \%)$ were women. Mean age was 38.7 years. Forty-two patients (60\%) had DRESS-DIHS, $12(17.1 \%)$ TEN, 5 (7.1\%) SJS, 6 (8.5\%) AGEP, 4 (5.7\%) other reactions not classified as SCARs, and 1 (1.4\%) overlapping SJS-TEN. The main causative drugs were aromatic anticonvulsants in 31 cases (44.3\%), B-lactam antibiotics in 11 cases (15.7\%), and non-B-lactam antibiotics in 6 cases (8.6\%). In all of the cases, the suspected drug was withdrawn at the first sign of a SCAR. Sixty-six patients (94.2\%) received anti-inflammatory treatment, mostly systemic corticosteroids. Complications occurred in 53 cases (75.7\%), and 3 patients died (4.3\%). Thirteen patients (18.6\%) had sequelae.

Conclusions: This is the first multicenter report on SCARs in Latin America. DRESS-DIHS was the most frequently reported clinical entity, and anticonvulsants were the main triggers. Most of the patients received systemic corticosteroids. Complications were frequent, and 3 patients died.
\end{abstract}

Key words: Drug eruptions. Stevens-Johnson syndrome. Toxic epidermal necrolysis. DRESS. Acute generalized exanthematous pustulosis. Latin America.

\section{Resumen}

Antecedentes: Las reacciones cutáneas graves inducidas por medicamentos (SCARs) presentan alta morbimortalidad y secuelas. Objetivo: Caracterizar clínicamente a pacientes con SCARs en ocho instituciones de salud de Latinoamérica.

Métodos: Estudio transversal, descriptivo, multicéntrico latinoamericano, de pacientes diagnosticados con SCARs, entre enero 2009 y diciembre 2018. El análisis se realizó a partir de una base de datos en BDClínic.

Resultados: Se reportaron 70 casos. 42 (60,8\%) eran mujeres. El promedio de edad fue de 38 años. 42 (60\%) tenían DRESS/DiHS, 12 $(17,1 \%)$ NET, $5(7,1 \%)$ SJS, 6 (8,5\%) PEGA, 4 (5,7\%) otras reacciones adversas cutáneas no clasificadas y 1 (1,4\%) NET-SJS superpuestos. Los principales fármacos involucrados fueron los anticonvulsivantes en 31 casos (44,3\%), los antibióticos betalactámicos en 11 (15,7\%) y los antibióticos no betalactámicos en $6(8,6 \%)$. A todos se les retiró el fármaco sospechoso ante los primeros signos de la reacción. Sesenta y seis pacientes $(94,2 \%)$ recibieron tratamiento antiinflamatorio, principalmente corticosteroides sistémicos. Las complicaciones ocurrieron en 53 casos (75,7\%) y la muerte en tres pacientes (4,3\%). Trece pacientes (18,6\%) tuvieron algún tipo de secuela. Conclusiones: Este es el primer estudio multicéntrico sobre SCARs en Latinoamérica. El DRESS/DiHS fue la reacción más frecuente y los anticonvulsivantes fueron los principales desencadenantes. La mayoría recibieron corticosteroides sistémicos. Las complicaciones fueron frecuentes y tres pacientes fallecieron.

Palabras clave: Reacciones cutáneas graves. Síndrome Stevens Johnson. Necrolisis Epidérmica Tóxica. DRESS. Pustulosis Exantemática Aguda. Latinoamérica. 


\section{Introduction}

Severe cutaneous adverse reactions induced by drugs (SCARs) cover a wide range of conditions that include Stevens-Johnson syndrome (SJS), toxic epidermal necrolysis (TEN), drug reaction with eosinophilia and systemic symptoms (DRESS), and drug-induced hypersensitivity syndrome (DIHS) [1,2]. Physicians also consider acute generalized exanthematous pustulosis (AGEP) to be a SCAR, given that it causes extensive eruptions and flares [2].

Despite their relatively low incidence, SCARs can be fatal and may have serious consequences. It is estimated that the incidence of SJS-TEN is 2 cases per million annually, while the incidence of DRESS for those who are treated with antiepileptic drugs is 1 out of every 1000 to 10000 patients [3].

TEN and SJS are characterized by damage to the epidermis and the mucosal epithelium and often lead to systemic complications. Both are considered variants of the same disorder, differentiated only by the body surface area (BSA) involved; thus, the reaction is considered to be SJS when skin damage is less than $10 \%$, overlap syndrome with SJS-TEN when damage is between $10 \%$ and $30 \%$, and TEN if the affected area exceeds $30 \%$. The drugs most commonly involved in SJS-TEN include anticonvulsants, allopurinol, antimicrobial agents, nonsteroidal anti-inflammatory drugs, and sulfonamides, although other drugs may also be involved [4].

DRESS and DIHS are associated with fever, hepatitis, and/or other internal organ complications, as well as lymphadenopathies and hematologic abnormalities (leukocytosis, hypereosinophilia, and atypical lymphocytosis). Reactivation of human herpesvirus (HHV), particularly HHV-6, has been reported in these conditions, as has cytomegalovirus, albeit less frequently. The drugs associated with DRESS-DIHS include aromatic anticonvulsants (carbamazepine, phenytoin, and phenobarbital), allopurinol, minocycline, antimicrobial sulfa drugs, and aromatic sulfonamides [5].

AGEP is probably the least severe type of SCAR. The reaction is characterized by nonfollicular pustules arising on edematous erythema. The rash is commonly accentuated in the main folds, with palmoplantar involvement being infrequent. The pustules are sterile and contain a large number of neutrophils. The most frequent causative drugs are the aminopenicillins, sulfonamides, quinolones, hydroxychloroquine, terbinafine, and diltiazem [6].

SCARs are considered to be delayed hypersensitivity reactions, with 4 subgroups identified: IVa, which are mediated by $\mathrm{T}_{\mathrm{H}} 1$ lymphocytes; IVb, which are mediated by $\mathrm{T}_{\mathrm{H}} 2$ lymphocytes, (interleukins 4,5 , and 13, and the cytokine eotaxin, as in DRESS); IVc, which are mediated by cytotoxic $\mathrm{T}$ lymphocytes (as in SJS and TEN); and IVd, which are mediated by $\mathrm{T}$ lymphocytes and neutrophils through IL-8 and granulocyte macrophage colony-stimulating factor (as in AGEP) [7].

Diagnosis of SCARs is essentially clinical, always after assessment of exanthema/skin characteristics, and latency period. Associated symptoms (eg, fever, pruritus, and lymphadenopathies) are also taken into account. SCARs must be managed with these reactions in mind, since early and appropriate multidisciplinary treatment has been associated with lower mortality and fewer subsequent problems [2].
While rare, SCARs are associated with complications such as bacterial superinfection, target organ compromise, multisystem organ failure, and, in the case of DRESS, frequent relapses. Several epidemiologic studies have established mortality rates of $10 \%-40 \%$ for SJS and TEN, $1 \%-10 \%$ for DRESS-DIHS, and 1\% for AGEP [8]. SJS and TEN can lead to dystrophic scars, hyperpigmentation, alopecia, nail loss, eye complications caused by synechiae, dry eye, symblepharon, tooth loss, genital synechiae, and psychiatric disorders. The consequences of DRESS-DIHS include autoimmune conditions such as lupus, thyroiditis, diabetes, and scleroderma [2].

Genetic factors have been associated with a predisposition to SCARs. Given that the genetic background of Latin American individuals differs from that of European, Asian, and African individuals, genetic factors may influence the incidence of SCARs in these populations. Unfortunately, in Latin America, there are no data on the incidence and clinical characteristics (clinical presentation, diagnosis, treatment, and prognosis) of SCARs. Inability to recognize the signs and symptoms of SCARs may lead to an increase in complications, sequelae, and mortality. Consequently, the main objective of the present study was to clinically define the patient with severe cutaneous reactions induced by drugs in 8 health care centers in 5 Latin American countries between 2009 and 2018.

\section{Methods}

We designed a multicenter, descriptive cross-sectional study in 8 health centers from 5 countries (Argentina, Brazil, Paraguay, Peru, and Colombia). The study conformed to the international recommendations of biomedical research as stated in the Declaration of Helsinki and the Council for International Organizations of Medical Sciences agreement.

The inclusion criteria are listed below. These were the same for all the health centers. The authors confirmed the cases by reviewing medical records and photographs.

\section{SJS-TEN}

The diagnosis was considered to be SJS-TEN in the presence of typical target-like lesions ( 2 sharply demarcated concentric rings surrounding an erythematous center) and according to the amount of blistering or detachment of the skin relative to the BSA.

- SJS: detachment below $10 \%$ of the BSA

- Overlap SJS-TEN: detachment between 10\% and 30\% of the BSA

- TEN detachment above $30 \%$ of the BSA [9]

\section{AGEP}

- Several dozen small, mostly nonfollicular pustules on a background of widespread edematous erythema

- Spongiform subcorneal and/or intraepidermal pustules and perivascular infiltrate with neutrophils and edema of the papillary dermis in histology

- Blood neutrophil counts above $7 \times 10^{9} / \mathrm{L}$

- Acute course with spontaneous resolution of pustules in less than 15 days. 
The inclusion criteria for AGEP were based on the 2001 score for validation of AGEP by Sidoroff et al [10], taking into account probable and definite cases.

\section{HSS/DRESS}

- Fever $>38.5^{\circ} \mathrm{C}$

- Enlarged lymph nodes

- Eosinophilia $>10 \%$ or $>700 / \mu \mathrm{L}$

- Atypical lymphocytes

- Skin involvement suggesting DRESS

- Involvement of at least 1 internal organ (liver, kidney, lung, muscle/heart, pancreas, other organ)

- Resolution $\geq 15$ days

- Other causes ruled out (hepatitis A, B, and C; EpsteinBarr virus; cytomegalovirus; Mycoplasma/Chlamydia; antinuclear antibody; blood culture).

The inclusion criteria for DRESS/DIHS were based on the 2007 diagnostic score for validation of DRESS/DIHS by Kardaun et al [11], taking into account probable and definite cases.

Diagnostic information was taken from physicians in the allergy/immunology departments of the participating institutions from January 2009 to December 2018. A thorough review of the clinical history was carried out to collect demographic characteristics, specific syndrome, drug involved, latency period, treatment established, and prognosis. Causality was evaluated using the ALDEN score for SJS-TEN [12] and

Table 1. Demographic and Clinical Characteristics of Patients with SCARs

\begin{tabular}{|c|c|c|c|c|c|}
\hline & $\begin{array}{c}\text { SJS-TEN } \\
(\mathrm{n}=18)\end{array}$ & $\begin{array}{c}\text { DRESS- } \\
\text { DIHS } \\
(n=42)\end{array}$ & $\begin{array}{c}\text { AGEP } \\
(n=6)\end{array}$ & $\begin{array}{l}\text { Other } \\
(n=4)\end{array}$ & $\begin{array}{c}\text { Total } \\
(n=70)\end{array}$ \\
\hline Age & $\begin{array}{c}34.3 \\
(21.8)\end{array}$ & $\begin{array}{c}4.2 \\
(2.1)\end{array}$ & $\begin{array}{c}36.3 \\
(14.9)\end{array}$ & $\begin{array}{l}45.2 \\
(2.1)\end{array}$ & $\begin{array}{c}38.7 \\
(2)\end{array}$ \\
\hline \multicolumn{6}{|l|}{ Sex } \\
\hline Female & $11(61)$ & $25(59.5)$ & $3(50)$ & $3(75)$ & $42(60)$ \\
\hline Male & $7(39)$ & $17(40.5)$ & $3(50)$ & $1(25)$ & $28(40)$ \\
\hline \multicolumn{6}{|l|}{ Country } \\
\hline Colombia & 15 & 22 & 3 & 4 & $44(62.8)$ \\
\hline Argentina & 2 & 8 & 1 & & $11(15.7)$ \\
\hline Brazil & & 7 & 2 & & $9(12.8)$ \\
\hline Paraguay & & 3 & & & $3(4.3)$ \\
\hline Peru & 1 & 2 & & & $3(4.3)$ \\
\hline \multicolumn{6}{|c|}{ Latency period } \\
\hline$<24 \mathrm{~h}$ & & 1 & & & $1(1.4)$ \\
\hline $24 \mathrm{~h}$ to $1 \mathrm{wk}$ & 5 & 4 & 5 & 2 & $16(22.9)$ \\
\hline 1 to $4 \mathrm{wk}$ & 10 & 24 & 1 & 2 & $37(52.9)$ \\
\hline 4 to $8 w k$ & 1 & 7 & & & 8 (11.4) \\
\hline$>8 \mathrm{wk}$ & 2 & 6 & & & $8(11.4)$ \\
\hline
\end{tabular}

Abbreviations: AGEP, acute generalized exanthematous pustulosis; DIHS, drug-induced hypersensitivity syndrome; DRESS, drug reaction with eosinophilia and systemic symptoms; SCARs, severe cutaneous adverse reactions induced by drugs; SIS-TEN, the whole spectrum of entities including overlapping SJS and TEN; TEN, toxic epidermal necrolysis.

avalues are presented as mean (SD) and No. (\%). the Naranjo score for DRESS and AGEP [13]. Data were collected using a modified version of the questionnaire of the European Network for Drug Allergies [14]. The BD Clinic software platform was used to create a database of patients with SCARs. Patients whose clinical records were incomplete and/or duplicates were excluded.

\section{Statistical Analysis}

A univariate analysis was carried out to determine the distribution of numeric variables. The normality of the distribution was contrasted using the Shapiro-Wilk test with $P<.05$. Normally distributed variables were summarized using measures of central tendency and dispersion (mean [SD] for a normal distribution, and median [IQR] for a nonnormal distribution). Data were analyzed using STATA version 14.

\section{Results}

We identified 72 cases of SCAR. Two patients were excluded owing to duplication, leaving a final study population of 70 patients. The demographic characteristics are shown in Table 1. The mean age was 38.7 (2) years, and 42 patients $(60 \%)$ were female. Forty-four patients were from Colombia, 11 from Argentina, 9 from Brazil, 3 from Paraguay, and 3 from Peru.

Of all the cases, $42(60 \%)$ were diagnosed with DRESS-DIHS, 18 with the whole spectrum of SJS-TEN (12 [17.1\%] with TEN, $5[7.1 \%]$ with SJS, and 1 [1.4\%] with overlap SJS-TEN), $6(8.5 \%)$ with AGEP, and $4(5.7 \%)$ with other nonclassified cutaneous adverse reactions (Figure). The reactions in DRESS-DIHS presented between the first and fourth week after initiation of the suspect drug in $57.1 \%$ of cases. This same latency period was recorded in $58.3 \%$ of the TEN cases, although this was shorter for AGEP, where $83.3 \%$ of the cases were observed less than 1 week after starting the causative drug.

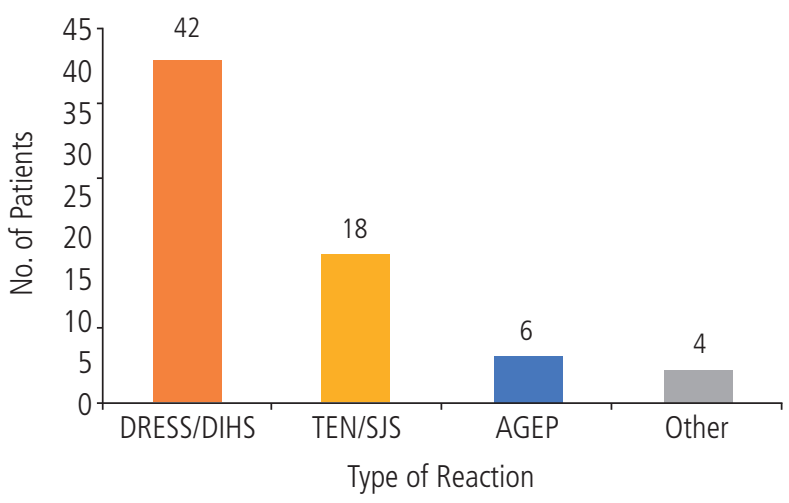

Figure. Type of Reaction. AGEP indicates acute generalized exanthematous pustulosis; DIHS, drug-induced hypersensitivity syndrome; DRESS, drug reaction with eosinophilia and systemic symptoms; SCARs, severe cutaneous adverse reactions induced by drugs; SJS-TEN, the whole spectrum of entities including overlapping SJS and TEN; TEN, toxic epidermal necrolysis. 
Table 2. Drugs Involved

\begin{tabular}{|c|c|c|c|c|c|}
\hline \multirow[b]{2}{*}{ Drug Involved } & \multirow[b]{2}{*}{ SJS-TEN $(\mathrm{n}=18)$} & \multirow[b]{2}{*}{ DRESS-DIHS $(\mathrm{n}=42)$} & \multicolumn{3}{|c|}{ Specific Syndrome ${ }^{a}$} \\
\hline & & & $\operatorname{AGEP}(\mathrm{n}=6)$ & Other $(n=4)$ & Total $(n=70)$ \\
\hline NSAIDS & $2(11.1)$ & $2(4.8)$ & & & $4(5.7)$ \\
\hline Acetylsalicylic acid & 1 & & & & 1 \\
\hline Diclofenac & & 1 & & & 1 \\
\hline Ibuprofen & 1 & & & & 1 \\
\hline Meloxicam & & 1 & & & 1 \\
\hline B-Lactam antibiotics & $3(16.7)$ & $4(9.5)$ & $3(50)$ & $1(25)$ & $11(15.7)$ \\
\hline Amoxicillin & 1 & 2 & 1 & & 4 \\
\hline Cefazolin & & & 1 & 1 & 2 \\
\hline Ceftriaxone & & 1 & & & 1 \\
\hline Meropenem & 1 & & & & 1 \\
\hline Benzathine penicillin $G$ & & 1 & 1 & & 2 \\
\hline Piperacillin-tazobactam & 1 & & & & 1 \\
\hline Non-ß-lactam antibiotics & $3(16.7)$ & $3(7.1)$ & & & $6(8.6)$ \\
\hline Azithromycin & & 1 & & & 1 \\
\hline Ciprofloxacin & 1 & 1 & & & 2 \\
\hline Clindamycin & 1 & & & & 1 \\
\hline Erythromycin & 1 & & & & 1 \\
\hline Vancomycin & & 1 & & & 1 \\
\hline Anticonvulsants & $5(27.7)$ & $25(59.5)$ & & $1(25)$ & $31(44.3)$ \\
\hline Carbamazepine & 3 & 12 & & & 15 \\
\hline Phenytoin & 1 & 11 & & & 12 \\
\hline Lamotrigine & 1 & 2 & & 1 & 4 \\
\hline Sulfonamides & & $1(2.3)$ & & & $1(1.4)$ \\
\hline Sulfamethoxazole-trimethoprim & & 1 & & & 1 \\
\hline Antiretroviral therapy & & $1(2.3)$ & & $1(25)$ & $2(2.8)$ \\
\hline Efavirenz & & 1 & & & 1 \\
\hline Nevirapine & & & & 1 & 1 \\
\hline Hyperuricemia treatments & $3(16.7)$ & $2(4.8)$ & & $1(25)$ & $6(8.6)$ \\
\hline Allopurinol & 3 & 2 & & 1 & 6 \\
\hline Antineoplastic drugs & 0 & 0 & 0 & 0 & $0(0.0)$ \\
\hline Other drugs & $2(11.1)$ & $4(9.5)$ & $3(50)$ & & $9(12.8)$ \\
\hline Acyclovir & & 1 & & & 1 \\
\hline Albendazole & 1 & & & & 1 \\
\hline Benznidazole & & 1 & & & 1 \\
\hline Escitalopram & & 1 & & & 1 \\
\hline Meglumine antimoniate & 1 & & & & 1 \\
\hline Metronidazole & & & 1 & & 1 \\
\hline Rosuvastatin & & & 1 & & 1 \\
\hline Terbinafine & & & 1 & & 1 \\
\hline \multicolumn{6}{|l|}{ No. of Drugs } \\
\hline 1 & & & & & $53(75.7)$ \\
\hline$\geq 2$ & & & & & $17(24.3)$ \\
\hline
\end{tabular}

Abbreviations: AGEP, acute generalized exanthematous pustulosis; DIHS, drug-induced hypersensitivity syndrome; DRESS, drug reaction with eosinophilia and systemic symptoms; NSAID, nonsteroidal anti-inflammatory drug; SCARs, severe cutaneous adverse reactions induced by drugs; SJS-TEN, the whole spectrum of entities including overlapping SJS and TEN; TEN, toxic epidermal necrolysis.

avalues are presented as No. (\%).

\section{Etiology}

The suspect drugs were identified in all patients, with causality considered probable in $38(54.3 \%)$, very probable or definite in $25(35.7 \%)$, and possible in $7(10 \%)$. The drug type and numeric distribution are shown in Table 2 . The main drugs involved were anticonvulsants in 31 cases (44.3\%), $\beta$-lactam antibiotics in 11 cases $(15.7 \%)$, and non- $\beta$-lactams in 6 cases $(8.6 \%)$.

In patients with DRESS-DIHS, the main triggers were anticonvulsants $(59.5 \%)$ and antibiotics (16.7\%). The most frequent anticonvulsant involved in DRESS-DIHS was 
carbamazepine (28.6\%), followed by phenytoin $(26.2 \%)$. In the case of TEN, anticonvulsants were involved in $41.7 \%$ of cases, antibiotics in $25 \%$, and allopurinol in $25 \%$. Antibiotics were the main suspected factor in SJS and AGEP (40\% and 50\% respectively). In 53 patients $(75.7 \%)$, only 1 causative drug was identified, while in the other $17(24.3 \%), 1$ suspected drug was reported and a second drug, less commonly associated with SCARs, was also identified.

The underlying conditions that justify the use of the causative drugs were convulsive disorders including epilepsy and structural alteration of the central nervous system in 20 cases $(28.6 \%)$, bacterial infections in 17 cases $(24.2 \%)$, and neuropathic pain in 6 cases $(8.6 \%)$. A skin biopsy was performed to support the diagnosis in 22 of the 70 patients $(31.4 \%)$.

\section{Treatment}

Once identified, the suspect causative drug was withdrawn from all of the patients, of whom $64(91.4 \%)$ were then treated with systemic corticosteroids and $9(12.8 \%)$ with intravenous immunoglobulin (IVIG). Seven patients $(10 \%)$ were treated with both therapies. When the patients were divided according to SCAR type, those with DRESS-DIHS received systemic corticosteroids. None of these patients received IVIG or cyclosporine, although 1 patient received infliximab plus a corticosteroid. Out of the 12 patients who presented with TEN, $10(83.3 \%)$ were treated with systemic corticosteroids and $6(50 \%)$ with IVIG; of these 6 patients, 4 were also given corticosteroids, 1 was given cyclosporine, and 1 was treated with infliximab. All the patients who presented with SJS were managed with systemic corticosteroids, 2 with IVIG plus corticosteroid, and 1 with cyclosporine plus corticosteroid.
Of the 6 patients with AGEP, 4 (66.7\%) received systemic corticosteroids and 2 were treated topically.

The median time between onset of the reaction and initiation of treatment was 5 (2-10) days, although this was shorter for SJS, TEN, and AGEP (3 [2-15], 3.5 [2.5-5.5], and 3 days [1-7], respectively) and longer for DRESS-DIHS (7 days [3-10]). In the only case of overlapping SJS-TEN, treatment started 21 days after onset of the reaction.

The median duration of treatment was 14 (7-30) days: 21 (14-30) for DRESS-DIHS, 6 (3-19.5) for TEN, and 10 (811) for SJS. All the patients with AGEP received treatment for 14 days (Table 3).

\section{Prognosis}

Hospital admission data, outcome, and prognoses are shown in Table 4. Out of 70 patients, $59(84.2 \%)$ required hospitalization, with a median duration of 10 (7-23) days. Patients diagnosed with SJS and TEN had a longer stay, namely, 12.5 (7.5-58.5) and 21.5 (8-29) days, respectively. Eight patients with DRESS-DIHS, 10 patients with TEN, 3 patients with SJS, 1 patient with AGEP, and the only patient with overlapping SJS-TEN were transferred to the intensive care unit, where the median stay was 5 (3-8), 16.5 (8-20), and 10 (3-85) days, for DRESS-DIHS, TEN, and SJS respectively.

Complications occurred in 53 cases $(75.7 \%)$. In patients with DRESS-DIHS, the most frequent complication was liver disease $(38 \%)$ followed by fluid and electrolyte disorders $(19 \%)$. Nine patients presented with sepsis as a complication ( 3 in the DRESS-DIHS group, 5 in the TEN group, and 1 in the SJS group).

Three patients (4.3\%) died ( 2 with TEN and 1 with SJS-TEN overlap). Sequelae were recorded in 13 cases (18.6\%), with

Table 3. Treatment ${ }^{\mathrm{a}}$

\begin{tabular}{|c|c|c|c|c|c|}
\hline & SJS-TEN $(\mathrm{n}=18)$ & DRESS-DIHS $(n=42)$ & $\operatorname{AGEP}(n=6)$ & Other $(n=4)$ & Total $(n=70)$ \\
\hline Suspected drug withdrawn & 18 & 42 & 6 & 4 & 70 \\
\hline $\begin{array}{l}\text { Systemic corticosteroid } \\
\text { Corticosteroid + IVIG }\end{array}$ & $\begin{array}{c}16 \\
7\end{array}$ & 42 & 4 & 2 & $\begin{array}{l}64(91.4) \\
7(10)\end{array}$ \\
\hline IVIG & 9 & & & & $9(12.8)$ \\
\hline $\begin{array}{l}\text { Cyclosporine } \\
\text { Cyclosporine }+ \text { corticosteroid }\end{array}$ & $\begin{array}{l}2 \\
2\end{array}$ & & $\begin{array}{l}1 \\
1\end{array}$ & & $\begin{array}{l}3(4.3) \\
3(4.3)\end{array}$ \\
\hline Infliximab & 2 & 1 & 1 & & $4(5.7)$ \\
\hline $\begin{array}{l}\text { Other treatment } \\
\text { Antihistamine } \\
\text { Colchicine } \\
\text { N-acetylcysteine } \\
\text { No data }\end{array}$ & $\begin{array}{l}3 \\
1 \\
1 \\
1\end{array}$ & $\begin{array}{l}4 \\
4\end{array}$ & $\begin{array}{l}3 \\
1\end{array}$ & & $\begin{array}{c}10(14.3) \\
5 \\
1 \\
1 \\
3\end{array}$ \\
\hline Treatment duration (days) & $7.5(3.2-12.5)$ & $21(14-30)$ & 14 & $10.5(5-30.5)$ & $14(7-30)$ \\
\hline Latency to treatment (days) & $3.5(2.2-6)$ & $7(3-10)$ & $3(1-7)$ & $6(2.5-34)$ & $5(2-10)$ \\
\hline
\end{tabular}

Abbreviations: AGEP, acute generalized exanthematous pustulosis; DIHS, drug-induced hypersensitivity syndrome; DRESS, drug reaction with eosinophilia and systemic symptoms; IVIG, intravenous immunoglobulin; SCARs, severe cutaneous adverse reactions induced by drugs; SJS-TEN, the whole spectrum of entities including overlapping SIS and TEN; TEN, toxic epidermal necrolysis.

avalues are presented as number (\%) and median (IQR). 
Table 4. Hospitalization and Outcome

\begin{tabular}{|c|c|c|c|c|c|c|c|}
\hline & $\begin{array}{l}\text { SJS } \\
(n=5)\end{array}$ & $\begin{array}{c}\text { TEN } \\
(\mathrm{n}=12)\end{array}$ & $\begin{array}{l}\text { SJS-TEN } \\
(\mathrm{n}=1)\end{array}$ & $\begin{array}{c}\text { DRESS-DIHS } \\
(\mathrm{n}=42)\end{array}$ & $\begin{array}{l}\text { AGEP } \\
(n=6)\end{array}$ & $\begin{array}{l}\text { Other } \\
(n=4)\end{array}$ & $\begin{array}{c}\text { Total } \\
(n=70)\end{array}$ \\
\hline Hospitalization & 4 & 12 & 1 & 35 & 4 & 3 & $59(84.3)$ \\
\hline Length of stay, $d$ & $\begin{array}{c}12.5 \\
(7.5-58.5)\end{array}$ & $\begin{array}{c}21.5 \\
(8-29)\end{array}$ & 51 & $\begin{array}{c}8 \\
(6-16)\end{array}$ & $\begin{array}{c}7 \\
(4.5-13)\end{array}$ & $\begin{array}{c}6 \\
(4-8)\end{array}$ & $\begin{array}{c}10 \\
(7-23)\end{array}$ \\
\hline ICU & 3 & 10 & 1 & 8 & 1 & & $23(32.9)$ \\
\hline ICU stay, $\mathrm{d}$ & $10(3-85)$ & $16.5(8-20)$ & 44 & $5(3-8)$ & 9 & & $9(4-19)$ \\
\hline $\begin{array}{l}\text { Complications } \\
\text { Sepsis } \\
\text { Fluid-electrolyte imbalance } \\
\text { Kidney failure } \\
\text { Hepatopathy } \\
\text { Multiorgan failure }\end{array}$ & $\begin{array}{l}4 \\
1\end{array}$ & $\begin{array}{c}12 \\
5 \\
1 \\
1 \\
1 \\
2\end{array}$ & 1 & $\begin{array}{c}35 \\
3 \\
8 \\
2 \\
16 \\
1\end{array}$ & & 1 & $\begin{array}{c}53(75.7) \\
9 \\
9 \\
3 \\
20 \\
5\end{array}$ \\
\hline Other complications & & 2 & & 5 & & & 7 \\
\hline In-hospital death & & 2 & 1 & & & & $3(4.3)$ \\
\hline Sequelae & 2 & 5 & & 4 & 1 & 1 & $13(18.6)$ \\
\hline Cutaneous alterations & 1 & 3 & & 3 & 1 & 1 & 9 \\
\hline Mucosal alterations & 0 & 0 & 0 & 0 & 0 & 0 & 0 \\
\hline Ocular alterations & 1 & 2 & & & & & 3 \\
\hline Depression & 0 & 0 & 0 & 0 & 0 & 0 & 0 \\
\hline Other sequelae & & & & 1 & & & 1 \\
\hline
\end{tabular}

Values are presented as number (\%) and median (IQR).

Abbreviations: AGEP, acute generalized exanthematous pustulosis; DIHS, drug-induced hypersensitivity syndrome; DRESS, drug reaction with eosinophilia and systemic symptoms; ICU, intensive care unit; SCARs, severe cutaneous adverse reactions induced by drugs; SJS, Stevens-Johnson syndrome; SJS-TEN, the whole spectrum of entities including overlapping SJS and TEN; TEN, toxic epidermal necrolysis.

cutaneous problems being the most frequent (12.8\%), followed by ophthalmological complications $(4.2 \%)$, such as loss of eyelashes, corneal scars, palpebral and conjunctival synechiae, and persistent photophobia.

\section{Discussion}

Ours is the first study in Latin America to characterize patients with SCARs to drugs in several countries. Consistent with previous studies [3,15-20], we observed that slightly more females were affected by SCARs.

The median age in this study was 38.7 years, which was similar to that reported by $\mathrm{Li}$ et al [21] in patients with SCARs in China, although lower than that reported by $\mathrm{Su}$ et al [22] in Singapore and in European populations according to the multinational registries EuroSCAR and RegiSCAR (European Registry of Severe Cutaneous Adverse Reactions to Drugs) $[3,15,18]$.

Most patients in this study presented with DRESS or DIHS, in contrast with findings from Asian and European studies [21-25], including one of the largest consortiums for the study of SCARs, the RegiSCAR project, where the main reaction observed was SJS. In their single-center study in Brazil, Botelho et al [26] found more patients with DRESS than SJS-TEN. Genetic factors in the Latin American population that may predispose individuals to DRESS-DIHS should be considered in the case of SCARs. Further pharmacogenomics studies are required to increase our understanding of these issues.

Although SCARs can be caused by various drugs, the most frequent culprits in this study were aromatic anticonvulsants, in contrast with other studies on SCARs, where antibiotics were the predominant causes [21,22,24,25], probably because there were more patients with DRESS-DIHS in the present study, where antiepileptic drugs were predominant. Similar findings have been reported for this syndrome elsewhere $[3,16,17]$. Consistent with data from other authors, the anticonvulsants responsible for the reactions were all aromatics (carbamazepine, phenytoin, and lamotrigine) [27,28]. Of these drugs, carbamazepine was the most frequent owing to its use not only in epilepsy, but also in other pain syndromes such as trigeminal neuralgia and neuropathic pain. Several pharmacogenomics studies carried out in Asian and European populations [29-31] have demonstrated the importance of identifying genes associated with SCARs, especially those caused by anticonvulsants. Consequently, it is very important to conduct genetic marker testing in the Latin American population. Such an approach may enable us to predict the future risk of SCARs and help to prevent them. After anticonvulsants, antibiotics, especially $ß$-lactams (15.7\%), were the group most associated with SCARs, and other studies have shown that bacterial 
infections were the second most common underlying condition requiring use of these antibiotics [21,24]. Allopurinol has also been frequently implicated in SCARs [3,22], although in our study, it was a potential cause of SCARs in 6 patients $(8.6 \%)$, 3 of whom had TEN, 2 DRESS or DIHS, and 1 AGEP. Fiftythree patients $(75.7 \%)$ were exposed to only 1 suspect drug, and 17 patients $(24.2 \%)$ received 2 or more drugs, with the additional drugs having a much lower risk of causing SCARs.

The latency period between intake and onset of the reaction varies according to the specific syndrome [3,22,24]. Of the patients who presented with DRESS-DIHS, 57.1\% exhibited symptoms between the first and fourth week after beginning treatment with the suspect drug, similar to patients with TEN, where $58.3 \%$ experienced reactions after 1 to 4 weeks. One case with DRESS had a latency period of less than 24 hours, which is unusual for this disease. However, Sahnoun et al [32] reported the case of a 47-year-old woman who developed DRESS syndrome 2 days after taking ciprofloxacin for a urinary infection in which the latency period was also short. In addition, application of the criteria of Naranjo et al [13] revealed the probability of an ADR to be possible. The reaction time was shorter for AGEP, where $83.3 \%$ developed a reaction less than a week after taking the causative drug, as also reported by Guevara-Gutierrez et al [33]. A total of 21 of the DRESS cases $(30.2 \%)$ were documented 4 weeks after initiation of treatment, including 6 patients who did not experience symptoms until after 2 months. This longer latency period in DRESS or DIHS, suggests that the early signs and symptoms of this reaction, such as fever, adenopathy, flu symptoms, odynophagia, and dysphagia, may be overlooked or confused with those of other, more frequent conditions.

Suspending treatment with the suspect agent is the most important step in managing SCARs. In this study, treatment with the suspect drug was terminated in all cases at the first signs or symptoms of SCARs. Many authors suggest the benefit of certain anti-inflammatory drugs [34-37]. Consistent with previous reports [22,24], 64 patients $(91.4 \%)$ in the present study received systemic corticosteroids. In the 1980s, it was suggested that the use of corticosteroids increased morbidity and mortality, not only owing to the increased risk of sepsis, but also because of a delay in re-epithelization [38]. However, a case-control analysis of selected patients from the EuroSCAR and RegiSCAR studies demonstrated that the long-term use of corticosteroids before onset of the reaction can extend latency and progression without adversely influencing severity or mortality [34]. Because of the low frequency of SCARs, the small number of clinical studies, and the ethical issues associated with administering placebo to patients who experience severe reactions, it is difficult to draw definitive conclusions regarding the anti-inflammatory management of patients with SJS-TEN. However, there does seem to be a benefit in treatment with methylprednisolone, IVIG, and cyclosporine when the observed mortality is compared with the expected rate using the SCORTEN score [39].

We found that systemic corticosteroids were administered to $100 \%$ of patients with DRESS. This finding was consistent with other studies, which also reported very frequent management with these drugs $[16,24,40,41]$. Corticosteroids have been considered the gold standard for treatment of
DRESS, leading to a rapid reduction in the appearance of fever and exanthema, as well as a rapid hepatic and hematologic response with decreased transaminases and eosinophilia [42]. Systemic therapy with corticosteroids must be initiated using a minimum dose of $1 \mathrm{mg} / \mathrm{kg} / \mathrm{d}$ of prednisone or its equivalent, with a gradual reduction over a period of 6-8 weeks. Prednisone must be maintained, even if there are signs of clinical improvement, to avoid the possibility of relapse. Additionally, DRESS patients have a high risk of developing immune reconstitution inflammatory syndrome if corticosteroids are interrupted suddenly $[40,43]$.

IVIG has also been used to treat SCARs, although this approach remains controversial. In the present study, only 9 patients $(12.8 \%)$ were managed with this drug, and all of them had SJS-TEN. Several noncontrolled, small-scale clinical studies reported conflicting results with the use of IVIG; one found no differences regarding mortality or progression [35], whereas the others showed favorable results [44-46].

Tumor necrosis factor (TNF) $\alpha$ released from inflammatory cells and activated keratinocytes in the epidermis play an important role in the immune response by inducing direct cytotoxicity and apoptosis [47]. Therefore, selective TNF blockade with infliximab has led to quick recovery from lesions in patients with TEN, some of whom received infliximab in monotherapy [48-51], or in combination with other systemic therapies $[52,53]$. It has also proven useful following failure of other systemic agents [50,54-58]. However, since none of the abovementioned studies are randomized control trials examining treatment of TEN, management of this disease continues to be controversial [59]. In the present study, infliximab was administered to 4 patients ( 2 with TEN, 1 with DRESS, and 1 with AGEP and associated psoriasis). The first patient was a 17-year-old woman who received carbamazepine for epilepsy. Two weeks later, she developed multiple blisters, loss of epidermis on $70 \%$ of her body surface, and mucous involvement. The patient was diagnosed with TEN (SCORTEN, 3). The culprit drug was withdrawn and support therapy started. She received $2 \mathrm{~g} / \mathrm{kg}$ of IVIG but did not improve; therefore, a single dose of $5 \mathrm{mg} / \mathrm{kg}$ of infliximab was administered. After 2 weeks, all the lesions had disappeared, although ocular sequelae (conjunctival synechiae) were reported. The second patient was a 5-yearold girl who had received allopurinol for chronic renal failure secondary to Henoch-Schönlein purpura. After 5 weeks, she developed diffuse rash with epidermal sloughing involving $100 \%$ of her body surface and was diagnosed with TEN (SCORTEN, 2). Given the extent of the lesions and the absence of improvement after $1 \mathrm{~g} / \mathrm{kg}$ of IVIG, she received $5 \mathrm{mg} / \mathrm{kg}$ of infliximab, and her symptoms improved considerably. No sequelae were observed. The third patient was a 13-year-old girl who developed DRESS after 6 weeks of treatment with carbamazepine for occipital lobe epilepsy. She received systemic corticosteroids, but developed multiorgan failure, with cardiac, hepatic, and renal involvement. Administration of $5 \mathrm{mg} / \mathrm{kg}$ of infliximab led to a gradual improvement in her skin lesions, laboratory findings, and general condition. However, she developed renal failure as a sequela. In 2018, Chua et al [60] reported a pediatric case series of DRESS and the first reported use of infliximab in a 14-year-old girl who developed 
DRESS due to cotrimoxazole. The patient was treated with systemic corticosteroids, azathioprine, cyclosporine A, and mycophenolate mofetil without improvement. Monthly IVIG, infliximab, topical corticosteroids, acitretin, and phototherapy were administered but proved ineffective. Further research is needed to evaluate the role of anti-TNF- $\alpha$ in DRESS. The fourth patient was a 50-year-old woman with associated psoriasis who received terbinafine for onychomycosis. One week later, she presented acute edematous erythema in skinfolds and on the face, followed by multiple small nonfollicular sterile pustules. Pustular psoriasis was ruled out due to the absence of conventional histological features of psoriasis and the strong association with a culprit drug (terbinafine), with relapse after involuntary administration. No improvement was observed after administration of systemic corticosteroids; therefore, she was given a single dose of infliximab $(5 \mathrm{mg} / \mathrm{kg})$, and her skin lesions had disappeared completely on day 14 .

There is no specific treatment for AGEP, except to discontinue the causative drug and provide clinical support based on the patient's status. AGEP is a self-limiting clinical entity with a favorable prognosis, although it can cause severe infection that may endanger patients with a poor general health status [19]. Of the 6 patients with AGEP in this study, $4(66 \%)$ received systemic corticosteroids, 1 cyclosporine, and 1 infliximab (see above). Systemic treatment was used more frequently than reported by Davidovici et al [19] and GuevaraGutierrez et al [33], where only $25 \%$ of the patients required it.

We recorded complications in $75.7 \%$ of cases, that is, more frequently than reported elsewhere [22], possibly because of the higher number of cases of DRESS-DIHS with liver disease as a complication (16,42\%). Liver disease is the main complication of patients with this syndrome and can affect as many as $87.5 \%$ or even $94.2 \%$ of patients [17]. As expected, sepsis was also frequently observed in patients with TEN (41.7\%) owing to the extended cutaneous involvement. McCullough et al [20] reported that $57.5 \%$ of their patients had complications with infections, mainly urinary tract infections (15\%), pneumonia (25\%), and bacteremia (17.5\%).

In this study, 3 patients $(4.3 \%)$ died. As all 3 had SJS-TEN, the mortality rate was $16.7 \%$, which is similar to previous reports [8] but higher than predicted by SCORTEN. The median SCORTEN in patients with SJS-TEN in the present study was 2 for predicting a mortality rate of $12.1 \%$ [61]. The individual SCORTEN scores were 3, 5, and 6, respectively.

Sequelae were recorded in 13 patients $(18.6 \%)$, mainly skin conditions (12.8\%), followed by ocular problems $(4.2 \%)$. This finding is consistent with data from other studies $[62,63]$. We found no psychiatric or autoimmune conditions, although a follow-up assessment of some patients may be needed to evaluate long-term effects and implications.

\section{Limitations}

The data reported here cannot be interpreted as a reliable sample of SCARs in Latin America, because they do not include all patients with SCARS in the 5 participating countries. However, given that there are referral centers in all 5 countries, many patients with SCARs are referred to one of these centers. Patients were diagnosed based on the clinical picture, and most did not undergo skin biopsy or subsequent in vivo testing (patch and intradermal test with late reading) or in vitro testing (lymphocyte transformation test) to assess the T-cell response to the suspect drug [64]. However, the true value of our study lies in the fact that it is the first study on SCARs in Latin America. It also provides the basis for further research, including identification of genetic markers from the Latin American population that are potentially associated with severe reactions and may thus help to prevent them.

\section{Conclusion}

This is the first study on SCARs in Latin America. DRESSDIHS was the most frequent reaction, and anticonvulsants were the main triggers. Most patients received systemic corticosteroids. Complications were frequent, and 3 patients died.

\section{Funding}

The authors declare that no funding was received for the present study.

\section{Conflicts of Interest}

The authors declare that they have no conflicts of interest.

\section{Previous Presentation}

Data from this study were presented in poster form at EAACI 2019, Lisbon, Portugal.

\section{References}

1. Roujeau JC, Stern RS. Severe adverse cutaneous reactions to drugs. N Engl J Med. 1994;331(19):1272-85.

2. Duong TA, Valeyrie-Allanore L, Wolkenstein $P$, Chosidow 0 . Severe cutaneous adverse reactions to drugs. Lancet. 2017;390(10106):1996-2011.

3. Kardaun SH, Sekula P, Valeyrie-Allanore L, Liss $Y$, Chu $C Y$, Creamer $D$, et al. Drug reaction with eosinophilia and systemic symptoms (DRESS): an original multisystem adverse drug reaction. Results from the prospective RegiSCAR study. $\mathrm{Br} J$ Dermatol. 2013;169(5):1071-80.

4. Roujeau JC. Stevens-Johnson syndrome and toxic epidermal necrolysis are severity variants of the same disease which differs from erythema multiforme. J Dermatol. 1997;24(11):726-9.

5. Shiohara T, Inaoka M, Kano Y. Drug-induced hypersensitivity syndrome (DIHS): a reaction induced by a complex interplay among herpesviruses and antiviral and antidrug immune responses. Allergol Int. 2006;55(1):1-8.

6. Alvarado SA, Munoz-Mendoza D, Bahna SL. High-risk drug rashes. Ann Allergy Asthma Immunol. 2018;121(5):552-60.

7. Pichler WJ, Naisbitt DJ, Park BK. Immune pathomechanism of drug hypersensitivity reactions. J Allergy Clin Immunol. 2011;127(3 Suppl):S74-81.

8. Schneck J, Fagot JP, Sekula P, Sassolas B, Roujeau JC, Mockenhaupt M. Effects of treatments on the mortality of 
Stevens-Johnson syndrome and toxic epidermal necrolysis: A retrospective study on patients included in the prospective EuroSCAR Study. J Am Acad Dermatol. 2008;58(1):33-40.

9. Bastuji-Garin S, Rzany B, Stern RS, Shear NH, Naldi L, Roujeau JC. Clinical classification of cases of toxic epidermal necrolysis, Stevens-Johnson syndrome, and erythema multiforme. Arch Dermatol. 1993;129(1):92-6.

10. Sidoroff A, Halevy S, Bavinck JN, Vaillant L, Roujeau JC. Acute generalized exanthematous pustulosis (AGEP)--a clinical reaction pattern. J Cutan Pathol. 2001;28(3):113-9.

11. Kardaun SH, Sidoroff A, Valeyrie-Allanore L, Halevy $S$, Davidovici BB, Mockenhaupt $M$, et al. Variability in the clinical pattern of cutaneous side-effects of drugs with systemic symptoms: does a DRESS syndrome really exist? $\mathrm{Br} J$ Dermatol. 2007;156(3):609-11.

12. Sassolas B, Haddad C, Mockenhaupt M, Dunant A, Liss Y, Bork $K$, et al. ALDEN, an algorithm for assessment of drug causality in Stevens-Johnson Syndrome and toxic epidermal necrolysis: comparison with case-control analysis. Clin Pharmacol Ther. 2010;88(1):60-8.

13. Naranjo CA, Busto U, Sellers EM, Sandor P, Ruiz I, Roberts EA, et al. A method for estimating the probability of adverse drug reactions. Clin Pharmacol Ther. 1981;30(2):239-45.

14. Demoly P, Kropf R, Bircher A, Pichler WJ. Drug hypersensitivity: questionnaire. EAACl interest group on drug hypersensitivity. Allergy. 1999;54(9):999-1003.

15. Mockenhaupt M, Viboud C, Dunant A, Naldi L, Halevy S, Bouwes Bavinck JN, et al. Stevens-Johnson syndrome and toxic epidermal necrolysis: assessment of medication risks with emphasis on recently marketed drugs. The EuroSCARstudy. J Invest Dermatol. 2008;128(1):35-44.

16. Sultan SJ, Sameem F, Ashraf M. Drug reaction with eosinophilia and systemic symptoms: manifestations, treatment, and outcome in 17 patients. Int J Dermatol. 2015;54(5):537-42.

17. Hiransuthikul A, Rattananupong $T$, Klaewsongkram J, Rerknimitr P, Pongprutthipan M, Ruxrungtham K. Drug-induced hypersensitivity syndrome/drug reaction with eosinophilia and systemic symptoms (DIHS/DRESS): 11 years retrospective study in Thailand. Allergol Int. 2016;65(4):432-8.

18. Sidoroff A, Dunant A, Viboud C, Halevy S, Bavinck JN, Naldi $L$, et al. Risk factors for acute generalized exanthematous pustulosis (AGEP)-results of a multinational case-control study (EuroSCAR). Br J Dermatol. 2007;157(5):989-96.

19. Davidovici B, Dodiuk-Gad R, Rozenman D, Halevy S, Israeli Regi SN. Profile of acute generalized exanthematous pustulosis in Israel during 2002-2005: results of the RegiSCAR Study. Isr Med Assoc J. 2008;10(6):410-2.

20. McCullough $M$, Burg $M$, Lin $E$, Peng $D$, Garner W. Steven Johnson Syndrome and Toxic Epidermal Necrolysis in a burn unit: A 15-year experience. Burns. 2017;43(1):200-5.

21. Li LF, Ma C. Epidemiological study of severe cutaneous adverse drug reactions in a city district of China. Clin Exp Dermatol. 2006;31(5):642-7.

22. Su P, Aw CW. Severe cutaneous adverse reactions in a local hospital setting: a 5-year retrospective study. Int J Dermatol. 2014;53(11):1339-45.

23. The RegiSCAR project [Internet Cited 2019 Feb 13].

24. Oh HL, Kang DY, Kang HR, Kim S, Koh Yl, Kim SH, et al. Severe Cutaneous Adverse Reactions in Korean Pediatric Patients: A
Study From the Korea SCAR Registry. Allergy Asthma Immunol Res. 2019;11(2):241-53.

25. Dibek Misirlioglu E, Guvenir H, Bahceci S, Haktanir Abul M, Can D, Usta Guc BE, et al. Severe Cutaneous Adverse Drug Reactions in Pediatric Patients: A Multicenter Study. J Allergy Clin Immunol Pract. 2017;5(3):757-63.

26. Botelho LF, Porro AM, Enokihara MM, Tomimori J. Adverse cutaneous drug reactions in a single quaternary referral hospital. Int J Dermatol. 2016;55(4):e198-203.

27. Yang CY, Dao RL, Lee TJ, Lu CW, Yang CH, Hung SI, et al. Severe cutaneous adverse reactions to antiepileptic drugs in Asians. Neurology. 2011;77(23):2025-33.

28. Blaszczyk B, Lason W, Czuczwar SJ. Antiepileptic drugs and adverse skin reactions: An update. Pharmacol Rep. 2015;67(3):426-34.

29. Chung WH, Chang WC, Lee YS, Wu YY, Yang CH, Ho HC, et al. Genetic variants associated with phenytoin-related severe cutaneous adverse reactions. JAMA. 2014;312(5):525-34.

30. Zeng T, Long YS, Min FL, Liao WP, Shi YW. Association of HLA-B*1502 allele with lamotrigine-induced StevensJohnson syndrome and toxic epidermal necrolysis in Han Chinese subjects: a meta-analysis. Int J Dermatol. 2015;54(4):488-93.

31. McCormack M,AlfirevicA, Bourgeois S, Farrell JJ, Kasperaviciute $D$, Carrington $M$, et al. HLA-A*3101 and carbamazepineinduced hypersensitivity reactions in Europeans. N Engl J Med. 2011;364(12):1134-43.

32. Sahnoun R, El Aidli S, Zaiem A, Lakhoua G, Kastalli S, Daghfous R. [DRESS syndrome induced by ciprofloxacine]. Nephrol Ther. 2015;11(2):111-3.

33. Guevara-Gutierrez E, Uribe-Jimenez E, Diaz-Canchola M, Tlacuilo-Parra A. Acute generalized exanthematous pustulosis: report of 12 cases and literature review. Int J Dermatol. 2009;48(3):253-8.

34. Lee HY, Dunant A, Sekula P, Mockenhaupt M, Wolkenstein $P$, Valeyrie-Allanore $L$, et al. The role of prior corticosteroid use on the clinical course of Stevens-Johnson syndrome and toxic epidermal necrolysis: a case-control analysis of patients selected from the multinational EuroSCAR and RegiSCAR studies. Br J Dermatol. 2012;167(3):555-62.

35. Bachot N, Revuz J, Roujeau JC. Intravenous immunoglobulin treatment for Stevens-Johnson syndrome and toxic epidermal necrolysis: a prospective noncomparative study showing no benefit on mortality or progression. Arch Dermatol. 2003;139(1):33-6.

36. Gilbert M, Ann Scherrer L. Efficacy and safety of cyclosporine in Stevens-Johnson syndrome and toxic epidermal necrolysis. Dermatol Ther. 2018:e12758.

37. Paradisi A, Abeni D, Bergamo F, Ricci F, Didona D, Didona B. Etanercept therapy for toxic epidermal necrolysis. J Am Acad Dermatol. 2014;71(2):278-83.

38. Halebian PH, Corder VJ, Madden MR, Finklestein JL, Shires GT. Improved burn center survival of patients with toxic epidermal necrolysis managed without corticosteroids. Ann Surg. 1986;204(5):503-12.

39. Carrillo D. ZL, Serrano C. Tratamiento antiinflamatorio en el síndrome de Stevens-Johnson y la necrólisis epidérmica tóxica: revisión sistemática de la literatura científica. Rev Asoc Colomb Dermatol. 2012;20(4):330-6. 
40. Chiou CC, Yang LC, Hung SI, Chang YC, Kuo TT, Ho HC, et al. Clinicopathological features and prognosis of drug rash with eosinophilia and systemic symptoms: a study of 30 cases in Taiwan. J Eur Acad Dermatol Venereol. 2008;22(9):1044-9.

41. Chen YC, Chiu HC, Chu CY. Drug reaction with eosinophilia and systemic symptoms: a retrospective study of 60 cases. Arch Dermatol. 2010;146(12):1373-9.

42. Natkunarajah J, Goolamali S, Craythorne E, Benton E, Smith C, Morris-Jones R, et al. Ten cases of drug reaction with eosinophilia and systemic symptoms (DRESS) treated with pulsed intravenous methylprednisolone. Eur J Dermatol. 2011;21(3):385-91.

43. Jevtovic DJ, Salemovic D, Ranin J, Pesic I, Zerjav S, DjurkovicDjakovic 0 . The prevalence and risk of immune restoration disease in HIV-infected patients treated with highly active antiretroviral therapy. HIV Med. 2005;6(2):140-3.

44. Tristani-Firouzi P, Petersen MJ, Saffle JR, Morris SE, Zone JJ. Treatment of toxic epidermal necrolysis with intravenous immunoglobulin in children. J Am Acad Dermatol. 2002;47(4):548-52.

45. Aires DJ, Fraga G, Korentager R, Richie CP, Aggarwal $S$, Wick J, et al. Early treatment with nonsucrose intravenous immunoglobulin in a burn unit reduces toxic epidermal necrolysis mortality. J Drugs Dermatol. 2013;12(6):679-84.

46 Trent JT, Kirsner RS, Romanelli P, Kerdel FA. Analysis of intravenous immunoglobulin for the treatment of toxic epidermal necrolysis using SCORTEN: The University of Miami Experience. Arch Dermatol. 2003;139(1):39-43.

47. Torres MJ, Mayorga C, Blanca M. Nonimmediate allergic reactions induced by drugs: pathogenesis and diagnostic tests. J Investig Allergol Clin Immunol. 2009;19(2):80-90.

48. Fischer M, Fiedler E, Marsch WC, Wohlrab J. Antitumour necrosis factor-alpha antibodies (infliximab) in the treatment of a patient with toxic epidermal necrolysis. $\mathrm{Br} J$ Dermatol. 2002;146(4):707-9.

49. Hunger RE, Hunziker T, Buettiker U, Braathen LR, Yawalkar N. Rapid resolution of toxic epidermal necrolysis with anti-TNFalpha treatment. J Allergy Clin Immunol. 2005;116(4):923-4.

50. Zarate-Correa LC, Carrillo-Gomez DC, Ramirez-Escobar AF, Serrano-Reyes C. Toxic epidermal necrolysis successfully treated with infliximab. J Investig Allergol Clin Immunol. 2013;23(1):61-3.

51. Chafranska L, Saunte DM, Behrendt N, Nygaard U, Christensen RJ, Sand C, et al. Pediatric toxic epidermal necrolysis treated successfully with infliximab. Pediatr Dermatol. 2019;36(3):342-5.

52. Gaitanis G, Spyridonos P, Patmanidis K, Koulouras V, Nakos G, Tzaphlidou $M$, et al. Treatment of toxic epidermal necrolysis with the combination of infliximab and high-dose intravenous immunoglobulin. Dermatology. 2012;224(2):134-9.

53. Patmanidis K, Sidiras A, Dolianitis K, Simelidis D, Solomonidis C, Gaitanis $G$, et al. Combination of infliximab and high-dose intravenous immunoglobulin for toxic epidermal necrolysis: successful treatment of an elderly patient. Case Rep Dermatol Med. 2012;2012:915314.
54. Al-Shouli S, Abouchala N, Bogusz MJ, Al Tufail M, ThestrupPedersen K. Toxic epidermal necrolysis associated with high intake of sildenafil and its response to infliximab. Acta Derm Venereol. 2005:85(6):534-5.

55. Wojtkiewicz A, Wysocki M, Fortuna J, Chrupek M, Matczuk $M$, Koltan A. Beneficial and rapid effect of infliximab on the course of toxic epidermal necrolysis. Acta Derm Venereol. 2008;88(4):420-1.

56. Kreft B, Wohlrab J, Bramsiepe I, Eismann R, Winkler M, Marsch WC. Etoricoxib-induced toxic epidermal necrolysis: successful treatment with infliximab. J Dermatol. 2010;37(10):904-6.

57. Worsnop F, Wee J, Natkunarajah J, Moosa Y, Marsden R. Reaction to biological drugs: infliximab for the treatment of toxic epidermal necrolysis subsequently triggering erosive lichen planus. Clin Exp Dermatol. 2012;37(8):879-81.

58. Scott-Lang $\mathrm{V}$, Tidman M, McKay D. Toxic epidermal necrolysis in a child successfully treated with infliximab. Pediatr Dermatol. 2014;31(4):532-4

59. Ganzetti G, Campanati A, Simonetti O, Giuliodori K Giangiacomi $M$, Lemme $G$, et al. Use of infliximab in toxic epidermal necrolysis: a still opened challenge. $\mathrm{G}$ Ital Dermatol Venereol. 2015;150(4):467-71

60. Chua GT, Rosa Duque JS, Chong PCY, Lee PPW, Lau YL, Ho MHK. Paediatric case series of drug reaction with eosinophilia and systemic symptoms (DRESS): 12-year experience at a single referral centre in Hong Kong and the first reported use of infliximab. Eur Ann Allergy Clin Immunol. 2018;50(6):273-6.

61. Bastuji-Garin S, Fouchard N, Bertocchi M, Roujeau JC, Revuz J, Wolkenstein P. SCORTEN: a severity-of-illness score for toxic epidermal necrolysis. J Invest Dermatol. 2000;115(2):149-53.

62. Olteanu $\mathrm{C}$, Shear NH, Chew HF, Hashimoto R, Alhusayen $\mathrm{R}_{\text {, }}$ Whyte-Croasdaile $S$, et al. Severe Physical Complications among Survivors of Stevens-Johnson Syndrome and Toxic Epidermal Necrolysis. Drug Saf. 2018;41(3):277-84.

63. Saka B, Akakpo AS, Teclessou JN, Mahamadou G, MouhariToure A, Dzidzinyo K, et al. Ocular and Mucocutaneous Sequelae among Survivors of Stevens-Johnson Syndrome and Toxic Epidermal Necrolysis in Togo. Dermatol Res Pract. 2019;2019:4917024.

64. Monge-Ortega OP, Cabanas R, Fiandor A, Dominguez-Ortega J, Gonzalez-Munoz M, Quirce S, et al. Overlap Between DRESS Syndrome and Exanthema Induced by Sulfadiazine in a Patient Treated With Sulfamethoxazole: Utility of the Lymphocyte Transformation Test for Identification of the Culprit Drug. J Investig Allergol Clin Immunol. 2018;28(2):132-4.

\section{Manuscript received August 22, 2019; accepted for publication February 14, 2020.}

\section{Carlos Daniel Serrano Reyes}

E-mail: cdserranoreyes@gmail.com 